\title{
Compostagem de resíduo sólido de abatedouro avícola
}

\author{
Composting of solid waste from poultry slaughterhouse
}

\begin{abstract}
Natália da Silva Sunada ${ }^{\mathrm{I}}$ Ana Carolina Amorim Orrico ${ }^{\mathrm{I}^{*}}$ Marco Antônio Previdelli Orrico Junior ${ }^{\mathrm{II}}$ Stanley Ribeiro Centurion ${ }^{\mathrm{II}}$ Arley Borges de Morais Oliveira ${ }^{\mathrm{IV}}$ Alexandre Rodrigo Mendes Fernandes ${ }^{\mathrm{II}}$ Jorge de Lucas Junior ${ }^{\mathrm{I}}$ Leonardo de Oliveira Seno ${ }^{\mathrm{II}}$
\end{abstract}

\section{RESUMO}

Em virtude da grande demanda por proteína de origem animal, tem-se aumentado a produção de frangos de corte e consequentemente a geração de resíduos provenientes do abate de aves, sendo necessário o desenvolvimento de técnicas que permitam o aproveitamento e reciclagem desses materiais. Objetivou-se com a execução deste trabalho avaliar a eficiência da compostagem no tratamento e reciclagem do resíduo sólido de abatedouro avícola. Utilizou-se resíduo sólido de abatedouro avícola comercial composto por fragmentos de vísceras, tecido muscular, adiposo e ósseo, sangue coagulado e penas e, como fonte de carbono, a casca de arroz. Montou-se uma leira com 1,5 $\mathrm{m}^{3}$ de volume inicial, na qual foram monitorados os parâmetros: temperatura, teores de sólidos totais $(S T)$, voláteis $(S V), N, P, K$, carbono orgânico (C), matéria orgânica compostável (MOC), matéria orgânica resistente à compostagem (MORC), demanda química de oxigênio (DQO), massa e volume enleirados, número mais provável (NMP) de coliformes totais e termotolerantes, bem como suas reduções durante o processo. A temperatura máxima atingida no centro da leira foi de $53,3^{\circ} \mathrm{C}$ (média semanal), já as reduções de massa de ST e SV e volume durante o processo de pré-compostagem foram de 36,$1 ; 44,3$ e 23,3\%, respectivamente, e, durante o processo de compostagem, foram de 21,8; 23,8 e 4,4\%. A baixa redução do volume das leiras pode estar associada à alta concentração de MORC $(40,1 \%)$ que pode ser principalmente relacionada à qualidade da fonte de carbono. O processo promoveu satisfatórias reduções totais de ST, SV e volume, sendo, respectivamente, 50,1; 57,5 e 26,7\%. No entanto, foram observadas reduções de $43 \%$ na quantidade de nitrogênio presente no composto final. Apesar das reduções de nitrogênio, a compostagem demonstrou ser um método eficiente no tratamento dos resíduos sólidos de abatedouro avícola.

Palavras-chave: matéria orgânica compostável, matéria orgânica resistente à compostagem, reciclagem de nutrientes, tratamento aeróbio.

\begin{abstract}
The great demand for animal protein was responsible for the increase on the broilers production and hence, the generation of waste from the poultry slaughter was increased as well, which in turn, propelled the development of techniques that allow the reuse and recycling of these wastes. The objective of this study was to evaluate the efficiency of composting on the treatment and recycling of solid waste from poultry slaughterhouse. The solid waste was from a commercial poultry slaughterhouse and was composed of viscera, muscle, fat, bone, blood and feathers that was mixed with a source of carbon, rice husk. Initially, a windrow with a volume of $1.5 \mathrm{~m}^{3}$ was built, and then some parameters were monitored: temperature, total solids (TS), volatile (VS), N, P, K, organic carbon $(C)$, composting organic matter (COC), organic matter resistant to composting (MORC), chemical oxygen demand (COD), mass and volume of the windrow, most probable number (MPN) of total and fecal coliforms, as well as their reductions during the process. The maximum temperature reached in the center of the windrow was $53.3^{\circ} \mathrm{C}$ (weekly average) since reductions of weight of TS and VS and volume during the pre-composting were 36.1, 44.3 and $23.3 \%$, respectively and during the composting process was $21.8,23.8$ and $4.4 \%$. The low volume reduction can be associated with high concentrations of MORC $(40.1 \%)$ which can be mainly related to the quality of the carbon source. The process produced satisfactory total reductions of TS, VS and volume that were respectively, 50.1, 57.5 and $26.7 \%$. However reductions were observed in $43 \%$ of amount of nitrogen in the final compound. Despite reductions in nitrogen content, composting proved to be an effective method in the treatment of solid waste from poultry slaughterhouse.
\end{abstract}

Key words: biodegradable organic matter, organic matter resistant to composting, recycling of nutrients, aerobic treatment.

\footnotetext{
'Universidade Estadual Júlio de Mesquita Filho (UNESP), Jaboticabal, SP, Brasil. anaorrico@ufgd.edu.br. *Autor para correspondência.

IIIUniversidade Federal de Goiás (UFG), Goiânia, GO, Brasil.

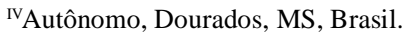

IIFaculdade de Ciências Agrárias, Universidade Federal da Grande Dourados (UFGD), 79804-970, Dourados, MS, Brasil. E-mail: 


\section{INTRODUÇÃO}

Segundo a União Brasileira de Avicultura (UBABEF, 2012), foram produzidos 13,05 milhões de toneladas de carne de frangos no Brasil no ano de 2011, caracterizando um crescimento de 6,8\% em relação a 2010, isto aproxima o Brasil da segunda maior produção mundial (China) com 13,2 milhões de toneladas. Juntamente com o aumento nos índices produtivos, cresce também a quantidade de resíduos provenientes do abate de aves, que acabam tornandose motivo de preocupação para a indústria da carne.

Os resíduos sólidos provenientes dos abatedouros de aves são compostos principalmente por fragmentos de vísceras, músculo, gordura, osso, sangue e penas, que, além de apresentarem alto potencial poluente, também podem ser fonte de transmissão de doenças. Para o tratamento desses resíduos, são necessárias técnicas especiais, que reduzam o potencial poluente e garantam a qualidade sanitária do material (ORRICO JUNIOR et al., 2010).

A técnica da compostagem vem apresentando resultados satisfatórios, sendo considerada por diversos autores (ORRICO et al., 2012; CESTONARO et al., 2010; PAIVA et al., 2012) uma importante forma de tratar os resíduos orgânicos. O processo ocorre por meio da estabilização da matéria orgânica em condições de altas temperaturas (superiores a $45^{\circ} \mathrm{C}$ ), obtendo-se um produto final estável, sanitizado, rico em compostos húmicos e cuja utilização no solo não oferece riscos ao meio ambiente (ORRICO JUNIOR et al., 2012).

Dessa forma, objetivou-se com a execução deste trabalho avaliar o processo de compostagem como uma alternativa no tratamento e reciclagem da fração sólida do resíduo de abatedouro de aves, com base na avaliação de parâmetros físicos, químicos e microbiológicos.

\section{MATERIAL E MÉTODOS}

Matéria-prima

Utilizaram-se resíduos sólidos de abatedouro avícola comercial composto por fragmentos de vísceras, tecido muscular, adiposo e ósseo, sangue coagulado e penas. O resíduo foi coletado logo após a evisceração e diretamente da canaleta de separação onde era disposto. Foram utilizados pequenos garfos, com abertura mínima de $5,0 \mathrm{~cm}$ entre as hastes, com a finalidade de separar os constituintes sólidos dos efluentes líquidos originados na evisceração. Após a coleta, o material foi acondicionado em vasilhames plásticos de 50 litros e transportado para o pátio de compostagem da Faculdade de Ciências Agrárias da Universidade Federal da Grande Dourados.

O resíduo sólido de abatedouro apresentou relação carbono:nitrogênio $(\mathrm{C}: \mathrm{N})$ média igual a 3,90 e teores médios de sólidos totais e voláteis de 46,66 e $42,85 \%$, respectivamente. Como fonte de carbono, utilizou-se casca de arroz, cuja relação $\mathrm{C}: \mathrm{N}$ foi igual a 60,37 e teores médios de sólidos totais e voláteis de 92,45 e $83,56 \%$, respectivamente. O substrato foi formado com $161 \mathrm{~kg}$ de casca de arroz e $289 \mathrm{~kg}$ de resíduo sólido de abatedouro avícola, respeitandose a relação de três partes do volume em material absorvente para cada parte de resíduo sólido, e adequando à umidade entre 40 a 60\% (ORRICO JUNIOR et al., 2010).

\section{Período de pré-compostagem}

$\mathrm{O}$ período de pré-compostagem compreendeu a fase que antecede à compostagem propriamente dita. Teve a duração de 60 dias $(10 / 12 / 2009$ a 11/02/2010) e foi realizada em uma composteira de alvenaria de dois metros de altura, piso de concreto e cobertura de telha de fibrocimento para evitar a entrada de água da chuva.

A disposição dos resíduos na composteira foi feita em camadas alternadas de casca de arroz e resíduo sólido do abate das aves, de forma que a primeira e a última camada fossem obrigatoriamente de casca de arroz. Nesta fase, optou-se pelo não revolvimento deste material pela sua constituição física e elevada carga orgânica, além da presença de elevados números de micro-organismos patogênicos.

\section{Período de compostagem}

Encerrado o período de pré-compostagem, a composteira foi aberta, a massa revolvida $\mathrm{e}$ homogeneizada, e o material resultante foi transferido para o pátio de compostagem, para a confecção de uma leira com dimensão de 2,3m de comprimento, $1,2 \mathrm{~m}$ de largura e 1,0m de altura. O pátio de compostagem apresentava piso de concreto com $2 \%$ de declividade para o escoamento do excesso de água e cobertura de telha de fibrocimento, para evitar a entrada de água da chuva e incidência solar direta.

A duração desta fase foi de 87 dias (11/02/2010 a 09/05/2010), período necessário para que o composto apresentasse temperatura no interior da leira semelhante à medida no ambiente $\left(25^{\circ} \mathrm{C}\right.$ média da temperatura do período) e relação $\mathrm{C}: \mathrm{N}$ próxima de 10:1, o que indica maturação do composto (Tabela 1).

Diariamente, efetuou-se o monitoramento da temperatura $\left({ }^{\circ} \mathrm{C}\right)$ por termômetro digital 
Tabela 1 - Reduções mais prováveis do número (NMP) de coliformes totais e termotolerantes durante a fase de compostagem do resíduo sólido de abate de aves + casca de arroz.

\begin{tabular}{lcc} 
& & \\
Período & Coliformes Totais & Coliformes Termotolerantes \\
\hline Início (61 dias) & $5,40 \mathrm{E}+09$ & $5,10 \mathrm{E}+09$ \\
Final (147 dias) & 0 & 0 \\
Redução (\%) & 100 & 100 \\
\hline
\end{tabular}

NMP: número mais provável.

introduzido totalmente no centro da leira e, semanalmente, realizou-se a pesagem $(\mathrm{kg})$ e mensuração do volume $\left(\mathrm{m}^{3}\right)$. Nessa ocasião, realizouse a aeração por revolvimento manual e adequou-se o teor de umidade por meio da irrigação da leira, além da coleta de amostras para quantificação dos teores de sólidos totais e sólidos voláteis, teores de carbono, nitrogênio, fósforo, potássio e NMP de coliformes totais e termotolerantes no início e final do processo.

Para determinação dos teores de ST e SV, as amostras obtidas semanalmente após a homogeneização da leira e coleta de uma alíquota representativa foram determinadas conforme metodologia descrita pela APHA (2005). Os conteúdos de carbono orgânico $(\mathrm{C})$, matéria orgânica compostável (MOC), matéria orgânica resistente à compostagem (MORC) e demanda química de oxigênio (DQO) foram estimados conforme proposto por KIEHL (1985). Para a quantificação dos teores de N, utilizou-se metodologia descrita por SILVA e QUEIROZ (2006). Os teores de P foram determinados, conforme metodologia descrita por MALAVOLTA (1989), e as concentrações de $\mathrm{K}$ foram determinadas em espectrofotômetro de absorção atômica. Os números mais prováveis (NMP) de coliformes totais e termotolerantes foram avaliados nas amostras coletadas no início e final do período de compostagem, por meio da técnica de tubos múltiplos, com base em metodologia descrita pela APHA (2005).

\section{RESULTADOS E DISCUSSÃO}

Observou-se que a temperatura foi superior a $40^{\circ} \mathrm{C}$ logo após o primeiro dia da compostagem e se manteve assim até $35^{\circ}$ dia do processo. A temperatura elevada durante um grande período de tempo foi fundamental para garantir a higienização (Figura 1) e redução da carga orgânica do material (Tabela 2).

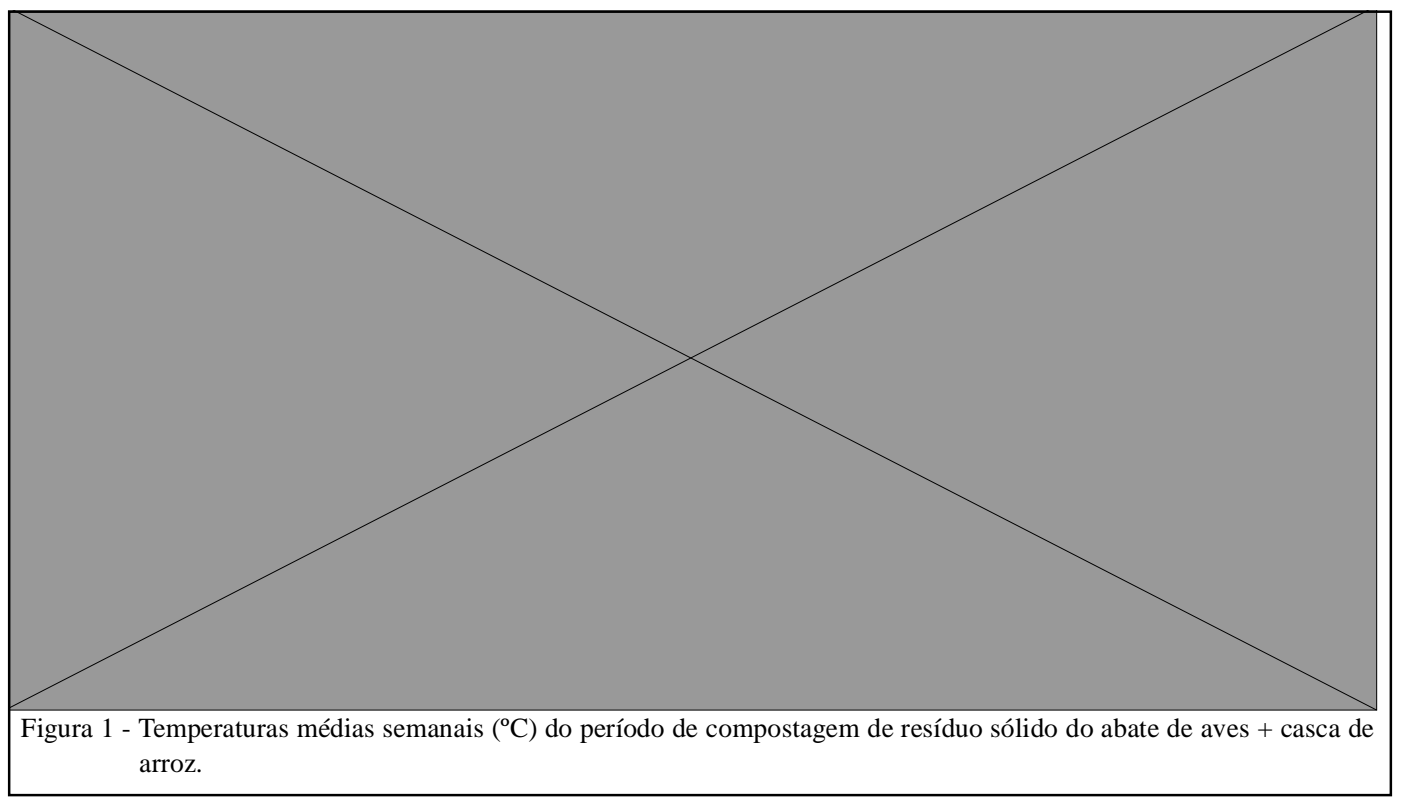

Ciência Rural, v.45, n.1, jan, 2015. 
Tabela 2 - Reduções de ST $(\mathrm{kg})$ e SV $(\mathrm{kg})$ e volume $\left(\mathrm{m}^{3}\right)$ durante as fases de pré-compostagem e compostagem do resíduo sólido de abate de aves + casca de arroz.

\begin{tabular}{llll}
\hline Substrato (período) & ST $(\mathrm{kg})$ & SV $(\mathrm{kg})$ & Volume $\left(\mathrm{m}^{3}\right)$ \\
\hline 1 dia* & 210,08 & 192,86 & 1,50 \\
60 dias & 134,33 & 107,47 & 1,15 \\
85 dias & 129,31 & 102,90 & 1,11 \\
106 dias & 111,95 & 86,86 & 1,11 \\
127 dias & 109,96 & 85,99 & 1,11 \\
147 dias & 104,98 & 81,94 & 1,10 \\
Redução Pré-compostagem(\%) & 36,06 & 44,27 & 23,33 \\
Redução compostagem $(\%)$ & 21,84 & 23,76 & 4,35 \\
Redução Total $(\%)$ & 50,03 & 57,51 & 26,67 \\
\hline
\end{tabular}

* As quantidades de sólidos totais (ST), sólidos voláteis (SV) e o volume foram determinados em cada material componente da massa enleirada (casca de arroz e resíduo de abatedouro avícola, separadamente) sendo os resultados apresentados, uma estimativa destas quantidades e do volume.

A análise microbiológica demonstrou a eficiência da compostagem na remoção de coliformes totais e termotolerantes durante o período experimental. As reduções observadas foram de $100 \%$ para coliformes totais e termotolerantes (Tabela 1). ORRICO JUNIOR et al. (2010) também observaram grande eficiência de $100 \%$ na eliminação de microrganismos patogênicos. Esta redução é de grande importância, uma vez que o produto final terá como destino o retorno ao solo na forma de fertilizante orgânico.

Durante a fase mesófila, predominam bactérias e fungos que degradam a matéria orgânica e liberam calor, por consequência favorecem o surgimento de actinomicetos, bactérias e fungos termófilos que degradam lipídeos, hemicelulose, celulose e lignina, sendo caracterizada desta forma a fase de redução da massa e volume enleirados (VALENTE et al., 2009). Este comportamento foi de extrema importância para os resíduos avaliados, pois o material utilizado como agente volumoso foi mais resistente à degradação e pode ter tido sua redução favorecida durante o processo em razão da adição do resíduo de abatedouro, que possuía maior facilidade à degradação e consequentemente colaborou para aquecimento da massa enleirada.

As maiores reduções de sólidos ocorreram na fase de pré-compostagem, na qual verificaram-se valores de $36,06 \%$ para a massa de ST e de $44,27 \%$ para a massa de SV (Tabela 2). Durante a fase de compostagem, a redução de ST foi de $21,84 \%$, valor semelhante ao encontrado por SIVAKUMAR et al. (2008), em que as reduções oscilaram entre 19,3 e
$48,6 \%$, ao efetuarem a compostagem de carcaças de aves e cama de frango. Considerando-se o somatório das duas fases (pré-compostagem e compostagem), as reduções de ST e SV foram satisfatórias, visto que os índices desejáveis estão acima de $50 \%$ de redução (KIEHL, 1985). Verificando-se os resultados obtidos por ORRICO JUNIOR. et al. (2010), notase que os valores encontrados durante a fase de compostagem foram superiores $(28,73 \%$ de redução de ST) aos deste trabalho. Este comportamento pode ser atribuído às diferenças na composição do material pré-compostado e compostado em ambas as condições, já que os autores utilizaram carcaças íntegras de aves e cama de frangos, o que caracteriza uma mistura com maior quantidade de matéria orgânica de fácil degradação, quando comparada à mistura de casca de arroz e fração sólida de resíduo de abatedouro avícola.

As maiores reduções do volume do substrato ocorreram durante a fase de précompostagem e corresponderam a 23,3\%. Já na fase de compostagem, a redução de volume foi de $4,3 \%$, resultando assim no total de $26,7 \%$ de redução durante todo o processo. É importante ressaltar que as maiores reduções da pré-compostagem podem estar associadas à presença do resíduo sólido de maneira íntegra e também à facilidade de degradação desta fração no início do processo.

Já a baixa redução de volume da fase de compostagem pode estar associada aos elevados teores de MORC (Tabela 3), o que diminui a capacidade dos microrganismos oxidarem $\mathrm{o}$ material e, consequentemente, reduzirem o volume 
Tabela 3 - Relação carbono e nitrogênio (C:N) e conteúdos de carbono (C), matéria orgânica compostável (MOC), matéria orgânica resistente à compostagem (MORC) e demanda química de oxigênio (DQO) do resíduo sólido de abate de aves + casca de arroz.

\begin{tabular}{|c|c|c|c|c|c|}
\hline Componentes & C:N & $\mathrm{C}(\%)$ & $\operatorname{MOC}(\%)$ & MORC (\%) & $\mathrm{DQO}\left(\mathrm{mg} \mathrm{g}^{-1}\right)$ \\
\hline Resíduo sólido do abate de aves & 3,90 & 21,47 & 38,04 & 61,30 & 572,29 \\
\hline Casca de arroz & 60,37 & 21,13 & 38,64 & 50,56 & 563,40 \\
\hline Substrato 1 dia & 11,36 & 21,23 & 38,46 & 53,73 & 566,02 \\
\hline Substrato 60 dias & 11,67 & 20,58 & 37,04 & 42,96 & 548,57 \\
\hline Substrato 106 dias & 12,80 & 20,47 & 36,84 & 41,36 & 545,61 \\
\hline Substrato 147 dias & 12,48 & 19,46 & 35,04 & 40,13 & 518,92 \\
\hline
\end{tabular}

Base na matéria seca.

enleirado, como mencionado por ORRICO JUNIOR et al. (2010). Outro parâmetro que reforça esta hipótese é a baixa redução da DQO do período de compostagem, que foi de aproximadamente $9,3 \%$. A média de redução de volume esperada seria em torno de 50\% (VALENTE et al., 2009) e, embora o valor observado neste trabalho tenha sido inferior, isto não descaracteriza o processo de compostagem como uma alternativa viável para tratamento deste resíduo, visto que os demais parâmetros avaliados apresentaram comportamento acima do esperado, e que a baixa redução de volume provavelmente foi associada à dificuldade de degradação da casca de arroz.

Observando os demais resultados de comportamento e eficácia da compostagem, acredita-se que a disponibilidade dos nutrientes foi satisfatória para manutenção da adequada atividade microbiana (Tabela 4). Observaram-se reduções nas quantias (em $\mathrm{kg}$ ) de nitrogênio (43\%) durante o período total de reciclagem (pré-compostagem e compostagem) do substrato. Este comportamento também foi observado por COSTA et al. (2006), que estudaram as concentrações de $\mathrm{N}$ durante a compostagem de aves mortas em diferentes sistemas de aeração, sendo que foram observados teores de $3,85 \%$ no início e $2,45 \%$ no final. TIQUIA \& TAM
(2000) avaliaram a compostagem dos resíduos de aviário e observaram decréscimo de $50 \%$ da amônia, entre o primeiro e sétimo dia de compostagem, e verificaram que somente a partir do $35^{\circ}$ dia, as concentrações mantiveram-se constantes. Os autores obtiveram redução de $59 \%$ de $\mathrm{N}$ na massa em relação ao inicial e atribuíram como causas principais das perdas de nitrogênio: a baixa relação $\mathrm{C}: \mathrm{N}$ do material, alta temperatura das leiras e $\mathrm{pH}$ acima de 7. Já o acréscimo nos teores de potássio observado se deve à concentração do nutriente em virtude da redução da matéria orgânica e nitrogênio obtido.

\section{CONCLUSÃO}

A compostagem demonstrou ser um método eficiente para o tratamento dos resíduos sólidos de abatedouro avícola. No entanto, são necessários novos estudos para tentar reduzir as elevadas perdas de nitrogênio observadas no composto final.

\section{AGRADECIMENTOS}

Os autores agradecem a Coordenação de Aperfeiçoamento de Pessoal de Nível Superior (CAPES) pela bolsa concedida.

Tabela 4 - Conteúdos de N, P e K (\% e kg) do resíduo sólido de abate de aves + casca de arroz.

\begin{tabular}{|c|c|c|c|c|c|c|}
\hline Componentes & $\mathrm{N}(\%)$ & $\mathrm{N}(\mathrm{kg})$ & $\mathrm{P}(\%)$ & $\mathrm{P}(\mathrm{kg})$ & $\mathrm{K}(\%)$ & $\mathrm{K}(\mathrm{kg})$ \\
\hline Resíduo sólido do abate de aves & 5,50 & 3,41 & 1,05 & 0,65 & 0,71 & 0,44 \\
\hline Casca de arroz & 0,35 & 0,52 & 0,07 & 0,10 & 0,31 & 0,46 \\
\hline Substrato 1 dia & 1,87 & 3,93 & 0,36 & 0,75 & 2,14 & 4,50 \\
\hline Substrato 60 dias & 1,76 & 2,37 & 0,54 & 0,72 & 6,07 & 8,16 \\
\hline Substrato 106 dias & 1,60 & 1,79 & 0,43 & 0,48 & 5,58 & 6,24 \\
\hline Substrato 147 dias & 1,56 & 1,64 & 0,38 & 0,40 & 5,58 & 5,85 \\
\hline
\end{tabular}

Base na matéria seca. 


\section{REFERÊNCIAS}

AMERICAN PUBLIC HEALTH ASSOCIATION (APHA). Standard methods for examination of water and wastewatern. 21.ed. Washington: American Water Works Association, 2005. $1368 \mathrm{p}$.

CESTONARO, T. et al. Desempenho de diferentes substratos na decomposição de carcaça de frango de corte. Revista Brasileira de Engenharia Agrícola e Ambiental, v.14, n.12, p.1318-1322, 2010. Disponível em: <http://www.scielo.br/scielo. php?script=sci_arttext\&pid=S1415-43662010001200010\&lng $=$ pt\&nrm=iso $>$. Acesso em: 21 mar. 2013. doi: 10.1590/S141543662010001200010 .

COSTA, M.S.S.M. et al. Desempenho de quatro sistemas para compostagem de carcaça de aves. Revista Brasileira de Engenharia Agrícola Ambiental, v.10, n.3, p.692698, 2006. Disponível em: <http://www.scielo.br/scielo. php? script $=$ sci_arttext $\&$ pid $=$ S $1415-43662006000300023 \& \operatorname{lng}$ =en\&nrm=iso $>$. Acesso em: 21 mar. 2013. doi: 10.1590/S141543662006000300023 .

KIEHL, E.J. Fertilizantes orgânicos. São Paulo: Agronômica Ceres, 1985. 492p.

MALAVOLTA, E. et al. Micronutrientes, uma visão geral. In FERREIRA, M.E.; CRUZ, M.C. Micronutrientes na agricultura. Piracicaba: POTAFOS / CNPq, 1989. p.1-33.

ORRICO JUNIOR, M.A.P. et al. Compostagem dos dejetos da bovinocultura de corte: influência do período, do genótipo e da dieta. Revista Brasileira de Zootecnia, v.41, n.5, p.1301-1307, 2012. Disponível em: <http://www.scielo.br/scielo.php?script=sci_ arttext\&pid=S1516-35982012000500030\&lng=pt\&nrm=iso $>$. ISSN 1806-9290. Acesso em: 21 mar. 2013. doi: 10.1590/S151635982012000500030 .

ORRICO JUNIOR. M.A.P. et al. Compostagem dos resíduos da produção avícola: cama de frangos e carcaças de aves. Engenharia
Agrícola, v.30, n.3, p.538-545, 2010. Disponível em: <http://www. scielo.br/pdf/eagri/v30n3/17.pdf >. Acesso em: 21 nov. 2010. doi: 10.1590/S0100-69162010000300017.

ORRICO, A.C.A. et al. Effect of different substrates on composting of poultry litter. Revista Brasileira de Zootecnia, v.41, n.7, p.1764-1768, 2012. Disponível em: <http://www.scielo.br/scielo. php?script=sci_arttext\&pid=S 1516-35982012000700028\&lng =pt\&nrm=iso>. Acesso em: 21 mar. 2013. doi: 10.1590/S151635982012000700028 .

PAIVA, E.R. et al. Avaliação da compostagem de carcaças de frango pelos métodos da composteira e de leiras estáticas aeradas. Engenharia Agrícola, v.32, n.5, p.961-970, 2012. Disponível em: <http://www.scielo.br/scielo.php?script=sci_arttext\&pid=S010069162012000500015\&lng=pt\&nrm=iso>. Acesso em: 21 mar. 2013. doi: 10.1590/S0100-69162012000500015.

SILVA, D.J. QUEIROZ, A.C. Análise de alimentos: métodos químicos e biológicos. 3.ed. Viçosa: UFV, 2006. 166p.

SIVAKUMAR, K. et al. Seasonal variations in composting process of dead poultry birds. Bioresource Technology, v.99, p.37083713, 2008. Disponível em: <www.sciencedirect.com>. Acesso em: 20 nov. 2010. doi: 10.1016/j.biortech.2007.07.023.

TIQUIA, S,M.; TAM, N.F.Y. Fate of nitrogen during composting of chicken litter. Environmental Pollution, v.110, n.4, p.535-541, 2000. Disponível em: <http://www.sciencedirect.com/science/ article/pii/S026974919900319X > . Acesso em: 21 mar. 2013. doi: 10.1016/S0269-7491(99)00319-X

UNIÃO BRASILEIRA DE AVICULTURA 9UBABEF0. Relatório Anual 2012. Brasília, DF, 2012. 57p. Disponível em: <http://www.abef.com.br>. Acesso em: 05 out. 12.

VALENTE, B.S. et al. Fatores que afetam o desenvolvimento da compostagem de resíduos orgânicos. Archivos de Zootecnia, v.58 (R), p.59-85, 2009. 